\title{
Symptom-based diagnosis of overactive bladder: an overview
}

\author{
Alan Wein, MD, FACS, PhD (Hon) \\ Division of Urology, University of Pennsylvania School of Medicine, Hospital of the University of Pennsylvania, Philadelphia, PA
}

Cite as: Can Urol Assoc J 2011;5(5Supp|2):S135-S136; D01:10.5489/cuaj.11183

\section{Abstract}

The current definition of overactive bladder (OAB) is "urgency, with or without urge incontinence, usually with frequency and nocturia in the absence of an underlying metabolic or pathologic condition." Urgency, in turn, is defined as a "sudden, compelling desire to pass urine that is difficult to defer." While these definitions provide the framework for making a clinical diagnosis of $\mathrm{OAB}$, they rely on subjective assessment of the symptoms by the patient. As well, the symptoms of OAB can be similar to those seen in other conditions, such as urinary tract infection, benign prostatic enlargement and bladder cancer. These other potential diagnoses should be ruled out in a noninvasive manner before making a diagnosis of OAB.

$\mathrm{F}$ or clinicians who treat patients with troublesome lower urinary tract symptoms, there is currently a reasonable consensus as to which symptoms are required for a diagnosis of overactive bladder (OAB). This is, however, based almost entirely on expert opinion; there is very little evidence available to validate these expert opinions. This review will summarize the current definitions and diagnostic criteria for $\mathrm{OAB}$, keeping in mind that this is an evolving field and that subsequent research may lead to changes in these criteria.

\section{History of the term "overactive bladder"}

The term "overactive bladder" was coined by Drs. Paul Abrams and Alan Wein in 1997 as a title for a symposium convened to discuss lower urinary tract symptoms and their treatment. ${ }^{1}$ One of the key goals of the conference was to develop a symptom-based definition of OAB. The guiding principles were to describe this common condition in a manner that was useful for both primary-care practitioners and specialists, that could imply initial, non-invasive therapy without the need for complicated, expensive, or invasive studies. The definition of $\mathrm{OAB}$, which was later formalized in 1999, was "a symptom syndrome suggestive of lower urinary tract dysfunction", specifically defined as "urgency, with or without urge incontinence, usually with frequency and nocturia in the absence of an underlying metabolic or pathologic condition" (Table 1). ${ }^{2}$ In 2002, the International Continence Society (ICS) formally adopted this definition. ${ }^{3,4}$

\section{Defining urgency}

Within the context of the definition of $O A B$, the word "urgency" also needs to be defined. The current definition is the "Sudden, compelling desire to pass urine that is difficult to defer." ${ }^{3}$ This was formally accepted by the ICS in 2002, replacing the previous definition: "Strong desire to void accompanied by fear of leakage or pain."

One of the ongoing criticisms of the current definition is the inclusion of the word "sudden." Some have argued that urgency may be the end result of a gradual build-up of sensation rather than always having a sudden onset. ${ }^{5}$ The reality may be that urgency can be either of these: it may be truly episodic with no prior urge to void, or it may occur as the final sensation following a gradual buildup of the urge to void. In this latter scenario, it is important to recognize that there may be a point where normal, physiologic urge changes to pathologic urgency.

\section{Potential problems with the current definitions}

One potential problem with the current definition of $O A B$ is that, by the inclusion of the word urgency, certain conditions are eliminated that might be more usefully included, such as detrusor overactivity causing incontinence but without sensation (what used to be termed "reflex incontinence"). This can also occur in the elderly with or without obvious neurologic disease. This condition would be treated in much the same way as $O A B$, but due to the current definition, would not qualify for $O A B$ diagnosis.

Similarly, the inclusion of the "in the absence of an underlying metabolic or pathologic condition" clause eliminates 
Table 1. Current definition of overactive bladder

- OAB is a "symptom syndrome", marked by urgency, with or without urge incontinence, usually with frequency and nocturia, in the absence of an underlying metabolic or pathologic condition.

- OAB: overactive bladder.

Table 2. Communicating the concept of urgency to patients

- Urgency is a feeling that comes on suddenly, making you want to rush to the bathroom because you fear that you may leak urine if you do not go right away

- You might think of it as:

- "When I have to go, I have to go" or

- "When I want to go, I have to rush because I think I may wet myself"

any symptoms secondary to urinary tract infection, cancer, stone, injury/surgery, adjacent inflammation and benign prostatic obstruction. Again, even though treatment of these symptoms may be similar to those for $\mathrm{OAB}$ as it is defined, the definition excludes patients with these underlying conditions from being diagnosed with OAB.

Furthermore, one of the inherent problems with the term urgency is that the symptoms are so subjective, it is difficult to assess objectively. The ICS definition of urgency can, therefore, be unclear when used in clinical trials and needs to be translated into an unequivocal form that the patient can understand. ${ }^{6}$ Table 2 shows some wording that may be used to describe urgency to patients.

\section{Differential diagnosis}

The symptoms of OAB can be similar to those seen in other conditions, such as urinary tract infection, benign prostatic enlargement and bladder cancer. As shown in Table 3, however, there are some differences that can help distinguish among these potential diagnoses without the need for invasive testing.

\begin{tabular}{lcccc}
\hline $\begin{array}{l}\text { Table 3. Differentiating overactive bladder from } \\
\text { conditions with similar symptoms }\end{array}$ & & \\
\hline $\begin{array}{l}\text { Presenting } \\
\text { symptom }\end{array}$ & “OAB” & UTI & Bladder Ca & BPH \\
Urgency & Yes & Yes & Occ & Freq \\
Frequency & Yes & Yes & Occ & Freq \\
UUI & $1 / 3$ & Occ & Occ & Occ/Freq \\
Nocturia & Yes & Yes & Rare & Freq \\
Pain/dysuria & No & Yes & Occ & Rare \\
Hematuria & No & Freq & Yes & Occ \\
Voiding Sx & No & No & No & Freq \\
\hline
\end{tabular}

OAB: overactive bladder; UTI: urinary tract infection; $\mathrm{Ca}$ : cancer; $\mathrm{BPH}$ : benign prostatic hyperplasia; UUI: urge urinary incontinence; Occ: occasionally; Freq: frequently. Modified from Nitti 2003, AUA presentation.

\section{Conclusions}

The current definition of $\mathrm{OAB}$, while useful for identifying patients with those criteria, is not perfect. As discussed in this short review, there are patients excluded from this diagnosis who, for practical purposes in selecting treatment options, could also be included in the OAB definition.

Competing interests: Dr. Wein is a consultant/advisor for Astellas, Allergan, Pfizer, Medtronic and Ferring.

This paper has been peer-reviewed.

\section{References}

1. Abrams P, Wein AJ, eds. The overactive bladder: From basic science to clinical management. Urology 1997;50(6 suppl):1-3.

2. Abrams $P$, Wein AJ. The overactive bladder and incontinence: Definitions and a plea for discussion. Neurourol Urodyn 1999:18:413-6.

3. Abrams $P$, Cardozo $L$, Fall $M$, et al. The standardisation of terminology of lower urinary tract function: report from the Standardisation Sub-committee of the International Continence Society. Neurourol Urodyn 2002;21:167-78

4. Abrams $P$, Cardozo L, Fall M, et al. The standardisation of terminology in lower urinary tract function: report from the standardisation sub-committee of the International Continence Society. Urology 2003;61:37-49.

5. De Wachter $S$, Wyndaele JJ. How sudden is a compelling desire to void? An observational cystometric study on the suddenness of this sensation. BJU Int 2008;101:1000-3.

6. Freeman RM. How urgent is urgency? A review of current methods of assessment. Int Urogynecol J Pelvic Floor Dysfunct 2005; 16:93-5.

Correspondence: Dr. Alan Wein, Perelman Center for Advanced Medicine, West Pavilion, 3rd Floor, 3400 Civic Center Blvd, Philadelphia, PA 19104; alan.wein@uphs.upenn.edu 